Stephen M. Klein MD,*

Roy A. Greengrass MD FRCPC,*

Stuart A. Grant MB CHB,*

Laurence $D$. H iggins $M D, \dagger$

Karen C. N ielsen M D,*

Susan M. Steele MD*

\title{
Ambulatory surgery for multi-ligament knee reconstruction with con- tinuous dual catheter peripheral nerve blockade
}

Purpose: Major reconstructive surgery of the knee traditionally requires an extended hospital stay for pain management. C ontinuous peripheral nerve blockade is an alternative method of pain control but is seldom used in the ambulatory setting. This case illustrates the use of lumbar plexus and sciatic nerve peripheral catheters for major knee surgery using intermittent bolus dosing for outpatient analgesia.

Clinical features: A 20-yr-old male presented for multi-ligamentous knee reconstruction (posterior collateral ligament and revision anterior collateral ligament and lateral collateral ligament). Anesthesia was managed with a lumbar plexus and a sciatic nerve peripheral catheter and a light general anesthetic. Post-operative analgesia was provided with a $12-\mathrm{hr}$ infusion of $0.2 \%$ ropivacaine in an over night recovery care centre. Subsequent catheter dosing was performed as an outpatient, twice a day using $0.2 \%$ ropivacaine, $10 \mathrm{ml}$ in each catheter (four injections total). This provided $96 \mathrm{hr}$ of analgesia and low supplemental opioid use.

Conclusion: The use of a lumbar plexus and sciatic nerve peripheral catheter offered an alternative to conventional pain control that worked well in the ambulatory setting. By providing prolonged unilateral lower limb analgesia, extensive knee surgery was performed that would normally require a hospital stay for pain control. U sing a bolus dosing method the risk of local anesthetic complications occurring outside of the hospital with a continuous infusion was minimized.

Objectif : Le soulagement de la douleur postopératoire d'une reconstruction majeure du genou nécessite habituellement un séjour prolongé à l'hôpital. Le blocage nerveux périphérique permet aussi de contrôler la douleur, mais est rarement utilisée en chirurgie ambulatoire. On présente un cas d'opération majeure du genou où l'analgésie ambulatoire a requis l'administration de bolus intermittents par cathéters périphériques au plexus lombaire et au nerf sciatique.

Élémentscliniques: Un homme de 20 ans devait subir une reconstruction multi-ligamentaire du genou (ligament collatéral postérieur et revue des ligaments collatéraux antérieur et latéral). Une anesthésie générale légère a été administrée, associée avec l'utilisation d'un cathéter périphérique au plexus lombaire et au nerf sciatique. L'analgésie postopératoire a consisté en une perfusion de ropivacaïne à $0,2 \%$, administrée pendant $12 \mathrm{~h}$, la première nuit, dans un centre de convalescence. Le dosage subséquent de l'analgésie par cathéter a été réalisé dans un contexte ambulatoire, deux fois par jour, avec de la ropivacaïne à $0,2 \%, 10 \mathrm{ml}$ dans chaque cathéter (quatre injections en tout). Cette technique a fourni $96 \mathrm{~h}$ d'analgésie et n'a demandé qu'un faible supplément d'opiö́de.

Conclusion : Le blocage périphérique du plexus lombaire et du nerf sciatique, en remplacement de la technique traditionnelle d'analgésie postopératoire, a été efficace dans un contexte ambulatoire. L'analgésie unilatérale prolongé du membre inférieur a permis une opération étendue du genou et évité l'habituel séjour hospitalier nécessaire au soulagement de la douleur postopératoire. Le dosage par bolus a réduit le risque de complications, reliés à l'anesthésique local, qui surviennent à l'extérieur de l'hôpital lorsqu'on utilise des perfusions continues.

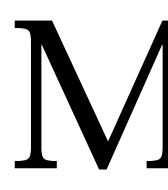

AJOR reconstructive surgery of the knee traditionally requires an extended hospital stay for pain management. Surgery such as total knee arthroplasty or multi-ligament reconstruction (as opposed to single anterior cruciate ligament repair) often involves a large incision, substantial soft tissue dissection and multiple osteotomies. As a result patients frequently require large doses of post-operative iv narcotics or continuous epidural analgesia. The care required to manage these modalities usually makes early hospital discharge difficult and prohibits performing this surgery on an ambulatory basis.

Continuous peripheral nerve blockade (CPNB) is an alternative technique that can provide prolonged

From the Departments of Anesthesiology* and Surgeryt, D uke U niversity M edical Center, D urham, N C, U SA.

A ddress correspondence to: Dr. Stephen M. Klein, D epartment of Anesthesiology, Box 3094, D uke U niversity M edical Center, D urham, NC 27710, USA. Phone: (919) 688-2056; Fax: (919) 668-2081; E-mail: klein006@mc.duke.edu

A ccepted for publication D ecember 4, 2000. 
post- operative analgesia and avoid many of the systemic side effects of opioid analgesia. ${ }^{1,2} \mathrm{H}$ owever, following major surgery on the knee joint the achievement of complete post-operative analgesia requires anesthetizing the innervation arising from both the lumbar and sacral plexus. As a result, because of the increased effort to anesthetize both neurologic distributions and the difficulty in managing two peripheral nerve catheters in the outpatient setting, CPNB is reserved for the hospital setting, and then most frequently a single peripheral nerve catheter is used. Further complicating the implementation of this technique is the concern for local anesthetic toxicity occurring outside of the hospital when continuous infusions of local anesthetics are employed.

We report a case of a patient undergoing multi-ligament knee reconstructive surgery. The patient was discharged to a hotel with both an indwelling lumbar plexus and sciatic nerve catheter. This case illustrates an alternative dosing strategy that allows physician evaluation and the delivery of local anesthetic in a monitored setting and bypasses the concern for toxicity occurring at home.

\section{C ase report}

A 20-yr-old healthy male, American Society of Anesthesiologist (ASA) physical status I, was scheduled for revision of right multi-ligament knee reconstruction (anterior, posterior and lateral cruciate ligaments) to repair damage from a traumatic injury. Previous repair of the anterior and lateral cruciate ligaments was unsuccessful, hence these were revision repairs. Physical examination revealed an otherwise healthy $121 \mathrm{~kg}, 186 \mathrm{~cm}$ male patient.

The patient was brought to the pre-operative holding area and standard institutional informed written consent for a continuous lumbar plexus and sciatic catheter was obtained. The potential for prolonged analgesia as well as the potential risks for an indwelling catheter were discussed. Because of the duration of surgery (estimated to be greater than six hours), and the request of the patient, a supplemental general anesthetic was planned as well.

After application of routine monitors and supplemental oxygen, the patient was sedated using iv midazolam $5 \mathrm{mg}$ and fentanyl $250 \mu \mathrm{g}$ in divided doses. $\mathrm{U}$ sing a nerve stimulator connected to an 18 gauge $150 \mathrm{~mm}$ insulated Tuohy needle (B. Braun M edical, Bethlehem, PA) attached via extension tubing to a syringe, the team performed a lumbar plexus block using the technique initially described by Winnie. ${ }^{3,4}$ With the patient's neck, back and hips flexed in the left lateral decubitus position a point was identified 4 $\mathrm{cm}$ lateral from midline along the intercristal line. At this point, the needle was advanced anteriorly until a quadriceps stimulus with a current less than $0.5 \mathrm{~mA}$ was elicited. After a negative aspiration for blood, 30 $\mathrm{ml}$ of $0.5 \%$ ropivacaine with $1: 400,000$ fresh epinephrine was injected in divided doses. Maintaining the needle in the same position, a 20 gauge standard epidural catheter was threaded $10 \mathrm{~cm}$ into the psoas compartment and secured with medical adhesive, cutaneous adhesive sutures, and an occlusive dressing. The sciatic nerve was blocked using the technique initially described by Labat. ${ }^{5}$ Again with the patient in the left lateral decubitus position, the right hip and leg was flexed. A line was drawn from the posterior superior iliac spine to the midpoint of the greater trochanter. Another line perpendicular from the midpoint of the first line was extended caudally $5 \mathrm{~cm}$. At this point, the needle was advanced perpendicular to the skin. Employing the same technique and needle, a plantar flexion stimulus was elicited with a current less than $0.5 \mathrm{~mA}$. In the same manner as the lumbar plexus block, a solution of $20 \mathrm{ml}$ of a $0.5 \%$ ropivacaine with 1:400,000 epinephrine was injected and the catheter inserted and secured. Successful neural blockade was documented approximately ten minutes after block placement by the loss of hip flexion and plantar flexion. The patient was then brought to the operating room and underwent general anesthesia. After induction with iv propofol $200 \mathrm{mg}$, the airway was secured using a laryngeal mask, and anesthesia was maintained with $\mathrm{N}_{2} \mathrm{O}$, oxygen and sevoflurane.

Substantial soft tissue dissection and numerous osteotomies were required during the surgical procedure. This included a $20-\mathrm{cm}$ incision made along the lateral aspect of the knee beginning at the midpoint laterally and extending down past the level of the tibial tubercle. In addition multiple bony tunnels were made in the femur, tibia and fibula for graft stabilization. A total of three separate bony tunnels were drilled on the tibia, two on the fibula, and four on the femur were drilled for ligament reconstruction. Total operating time was $245 \mathrm{~min}$. Estimated blood loss was $600 \mathrm{ml}$.

At the conclusion of the case the patient emerged from anesthesia uneventfully and was transferred to the post- anesthesia care unit. $\mathrm{H}$ e was pain free with complete motor blockade of the right lower extremity. After negative aspiration from the lumbar plexus catheter and a negative test dose using 1.5\% lidocaine with 1:200,000 epinephrine $(5 \mathrm{ml})$, a continuous infusion of $0.2 \%$ ropivacaine at $10 \mathrm{ml} \cdot \mathrm{hr}^{-1}$ was begun. The patient was then transferred to the $23 \mathrm{hr}$ recovery care unit with a plan to bolus the sciatic catheter and the lumbar plexus catheter as necessary for refractory 
pain. $\mathrm{H}$ e was prescribed oral ibuprofen $600 \mathrm{mg}$ three times a day for three days. In addition, cold therapy was provided to the knee via a Wrapon Polar Pad ${ }^{\circledR}$ (Breg, Vista, CA).

On post-operative night one the patient complained of dull aching knee pain approximately $18 \mathrm{hr}$ after the initial blockade. $\mathrm{He}$ received oral acetaminophen $350 \mathrm{mg}$ with $5 \mathrm{mg}$ oxycodone and the lumbar plexus catheter was bolused with $10 \mathrm{ml}$ of $0.2 \%$ ropivacaine, using incremental injection. The patient received complete analgesia.

On post-operative day one the continuous infusion was discontinued and both the lumbar plexus and sciatic nerve catheters were bolused with $10 \mathrm{ml}$ of $0.2 \%$ ropivacaine with 1:400,000 epinephrine, using incremental injection. Despite excellent analgesia, gross motor function remained intact. The patient was given specific instructions to protect the insensate extremity, a telephone number of a contact physician and a return appointment that evening. $\mathrm{He}$ was then discharged from the recovery care unit to a local motel. That evening (post-operative day one), the patient returned to the ambulatory surgery centre to have his catheters redosed. During the course of the day he took two oral acetaminophen $350 \mathrm{mg}$ with $5 \mathrm{mg}$ oxycodone tablets. At that time his verbal analog pain score was $2(0=$ no pain / $10=$ the worst pain imaginable). After routine monitoring, he received a second bolus of $10 \mathrm{ml}$ of $0.2 \%$ ropivacaine, using incremental injection, into both catheters and his pain decreased to a score of zero. D espite the profound analgesia, lower extremity motor function was grossly intact.

The patient returned to the ambulatory surgery centre on the morning of post-operative day two. During the evening he consumed one oral acetaminophen 350 $\mathrm{mg}$ with $5 \mathrm{mg}$ oxycodone tablet for insomnia. $\mathrm{He}$ had no complaints of pain. Both catheters were bolused with $10 \mathrm{ml}$ of $0.5 \%$ ropivacaine with 1:400,000 epinephrine, using incremental injection, in anticipation of the motion and jarring during a long car ride home. The patient returned home, took one more oral acetaminophen $350 \mathrm{mg}$ with $5 \mathrm{mg}$ oxycodone tablet for insomnia and remained pain free until the morning of post-operative day three, over $96 \mathrm{hr}$ from the initial blockade. On our routine seven-day patient follow-up, he was highly satisfied with his care, especially when comparing it to his previous knee reconstruction. $\mathrm{He}$ had no appreciable residual motor or sensory blockade.

\section{Discussion}

U tilizing both a lumbar plexus and a sciatic nerve peripheral catheter for major knee surgery in ambulatory surgery patients has not been reported. By administering local anesthetic directly near both the lumbar plexus and the sciatic nerve, prolonged analgesia was achieved for extensive lower extremity orthopedic surgery, which would otherwise have required iv narcotics and a prolonged hospital admission. Typical iv narcotic requirements for other patients, having similar surgery at our institution, are greater than $100 \mathrm{mg}$ of morphine sulfate over three days (unpublished data).

Recently the use of continuous outpatient axillary nerve sheath catheters and sciatic catheters have been reported with encouraging results but because of the dual innervation of the knee this has been difficult for extensive outpatient joint surgery. ${ }^{6,7} \mathrm{M}$ ajor surgery of the knee joint requires anesthesia of both the lumbar plexus and the sciatic nerve. The knee joint is innervated primarily by the femoral nerve. However, the knee is also innervated by the obturator and sciatic nerves. These include the $L 2, L 3$, and $L 4$ dermatomes and the $L 3, L 4, L 5$, and $S 1$ osteotomes. In addition, this patient's incision extended along the lateral leg distal to the knee, an area which involves the L5 and S1 dematomes. As a result, to achieve complete analgesia both a lumbar plexus and sciatic block were essential. U nfortunately, a single peripheral nerve block that anesthetizes both the lumbar plexus and sciatic nerve is currently unavailable. Although single femoral catheters have been effective for reducing analgesia after knee surgery, complete analgesia was necessary in this patient who was being discharged. I $\mathrm{n}$ order to provide complete unilateral anesthesia to this large area, the anesthesia team elected to employ two catheters. The psoas compartment technique was used to place the lumbar plexus catheter. This approach places the catheter and local anesthetic at the level of the nerve roots. U tilizing this level of neural blockade is particularly effective when anesthesia of the femoral, obturator, and lateral femoral cutaneous nerves is desired. ${ }^{8}$

Continuous lumbar plexus and sciatic anesthesia have been shown to decrease analgesia requirements and speed rehabilitation. H owever, despite these benefits, use of continuous catheters and their application for ambulatory surgery has been limited. O ne principal impediment is the concern for local anesthetic toxicity occurring outside the hospital when continuous infusions of local anesthetic are used. This case illustrates an alternative dosing strategy that allows physician evaluation and the delivery of local anesthetic in a monitored setting and bypasses the concern for toxicity occurring at home.

The technique provided analgesia for the entire lower extremity for approximately $96 \mathrm{hr}$. This duration is substantially longer than that provided by sin- 
gle injection nerve blockade alone. In addition, it offers the advantage of anesthetizig only the affected lower extremity. This allows patients to ambulate using crutches and avoids some of the side effects of opioids and epidural anesthesia. The technique also incorporates other treatment modalities such as cold therapy and non-steroidal anti-inflammatory drugs to aid in decreasing pain and inflammation.

Despite the potential benefits of improved analgesia and facilitated discharge after major surgery, several limitations with this technique still exist. The need for repeated outpatient visits for analgesia is a potential disadvantage and may be challenging, depending on the structure and resources of a busy ambulatory centre. The level of analgesia and the ability to remain as an outpatient however may outweigh the additional intervention from the anesthesia team and patient inconvenience. Another drawback of discharging patients after major surgery is the limited resources available to address potential breakthrough pain at home, the need for skilled nursing care, or the potential for post-operative bleeding. I n addition, restricted mobility or limited patient autonomy may complicate care. Furthermore, although discharging patients with an insensate extremity has been done routinely at our institution for over nine years, the potential for injury or the inability to access neurologic function still exists. In addition, despite the theoretical compliance of the perineural areas instrumented in this case, data concerning the risk of hematoma formation in patients treated with peri-operative anticoagulation for deep venous thrombosis prevention are not available.

In summary, this anesthetic technique was well received by the patient and the surgeon. The technique offered an alternative to conventional pain control that worked well in the ambulatory setting. In addition, by providing prolonged unilateral lower limb analgesia, extensive knee surgery was performed on an ambulatory basis that would normally have required a hospital stay for pain control.

\section{References}

1 Sada T, K obayashi T, Murakami S. Continuous axillary brachial plexus block. Can Anaesth Soc J 1983; 30: 201-5.

2 Stinson LW, Lennon R L, A damsR A, M orrey BF. The technique and efficacy of axillary catheter analgesia as an adjunct to distraction elbow arthroplasty: a prospective study. J Shoulder Elbow Surg 1993; 2: 182-9.

3 Steele S, K lein S, D'Ercole F, Greengrass R, Gleason D. A new continuous catheter delivery system (Letter). Anesth Analg 1998; 86: 228.

4 WinnieA P, R amamurthy S, D urrani Z, R adonjic R. Plexus blocks for lower extremity surgery. $\mathrm{N}$ ew answers to old problems. Anesthesiology Review 1974; 1: 11-6. 5 R aj PP, Pai U, R awal N. Techniques of regional anesthesia in adults. In: Raj PP (Ed.). Clinical practice of regional anesthesia. $\mathrm{N}$ ew York: Churchill Livingstone Inc., 1991: 307-9.

6 R awal N, A xelsson K, H ylander J, et al. Postoperative patient- controlled local anesthetic administration at home. Anesth Analg 1998; 86: 86-9.

7 K lein SM, Greengrass R A, Gleason DH, N unley JA, Steele SM. M ajor ambulatory surgery with continuous regional anesthesia and a disposable infusion pump. Anesthesiology 1999; 91: 563-5.

8 Mansour NY, Bennetts FE. An observational study of combined continuous lumbar plexus and single-shot sciatic nerve blocks for post-knee surgery anal gesia. Reg Anesth 1996; 21: 287-91. 